\title{
Interleukin-32 stimulates osteosarcoma cell invasion and motility via AKT pathway-mediated MMP-13 expression
}

\author{
YANHONG ZHOU ${ }^{1}$, ZHAOHUI HU ${ }^{2}$, NINGNING $\mathrm{LI}^{2}$ and RENJIE JIANG ${ }^{2}$ \\ Departments of ${ }^{1}$ Clinical Laboratory and ${ }^{2}$ Spine Surgery, The People's Hospital of Liuzhou, Liuzhou 545006, P.R. China
}

Received June 28, 2014; Accepted March 9, 2015

DOI: $10.3892 / \mathrm{ijmm} .2015 .2159$

\begin{abstract}
As a pro-inflammatory cytokine, interleukin-32 (IL-32) is reported to play an important role in tumor development and progression. However, its effects on the invasion and motility of osteosarcoma cells remain elusive. The aim of the present study was to determine the molecular mechanisms of IL-32 in osteosarcoma cells using RT-PCR and western blot analysis. The results showed that IL-32 stimulation dose-dependently promoted the invasion and motility of osteosarcoma cells. Knockdown of endogenous IL-32 by siRNA inhibited osteosarcoma cell invasion and motility. Moreover, IL-32 induced the activation of AKT in a time-dependent manner. IL-32 stimulation was also capable of increasing the expression and secretion of matrix metalloproteinase (MMP)-13, which is involved in tumor invasion and metastasis. In addition, blockade of AKT activation suppressed IL-32-mediated invasion, motility and MMP-13 upregulation in osteosarcoma cells. Taken together, our results suggest that IL-32 stimulation promotes the invasion and motility of osteosarcoma cells, possibly via the activation of AKT and the upregulation of MMP-13 expression. Thus, IL-32 may serve as a marker for diagnosis, as well as for the treatment of osteosarcoma.
\end{abstract}

\section{Introduction}

Osteosarcoma is the most common primary malignant bone tumor that predominantly affects children and adolescents (1). Although traditional therapies such as chemotherapy, surgery and radiotherapy have been developed, the 5-year survival rates of osteosarcoma patients remain at only $60-70 \%$ (2). Invasion and metastasis are responses leading to mortality of osteosarcoma patients. The metastasis of osteosarcoma is mainly hematogenous, and often occurs in the distal organs, such as lungs (3). In many cases, osteosarcomas have already metastasized at the time of diagnosis (4). Therefore,

Correspondence to: Dr Zhaohui Hu, Department of Spine Surgery, The People's Hospital of Liuzhou, 8 Wen Chang Road, Liuzhou 545006, P.R. China

E-mail: zhaohuihulz@163.com

Key words: interleukin-32, invasion, motility, AKT, matrix metalloproteinase-13, osteosarcoma identification of the molecular mechanisms underlying osteosarcoma invasion and metastasis, and improvement of new clinical approaches for the diagnosis and therapy of osteosarcoma is crucial.

Accumulating evidence suggests that the levels of many inflammatory cytokines are increased in the tumor microenvironment, and these inflammatory cytokines play crucial roles in the progression of cancer, including cell growth, invasion and metastasis $(5,6)$. Interleukin-32 (IL-32) is a type of inflammatory cytokine that is mainly produced by $\mathrm{T}-$, natural killer, epithelial cells and monocytes after stimulation by IL-2, IL-18 or IFN- $\gamma(7,8)$. The $I L-32$ gene is located on human chromosome 16p13.3, and has six splice variants, IL-32 $\alpha$, IL-32 $\beta$, IL-32 $\gamma$, IL-32 $\delta$, IL-32 $\varepsilon$ and IL-32 $\zeta$ (9). Although the receptor for IL-32 remains to be determined, IL-32 has been found to stimulate TNF- $\alpha$, IL- $1 \beta$ and IL- 8 production and thus act as a pro-inflammatory mediator in inflammatory diseases and tumor $(7,10)$. IL-32 expression is increased in malignant esophageal tissues (11), and overexpression of IL-32 is reversely associated with 5-year recurrence-free, disease-specific and overall survival rates in localized clear cell renal cell carcinoma (12). However, the role of IL-32 in osteosarcoma progression remains to be elucidated. In the present study, we focused on the effects of IL-32 on cell invasion and motility, and aimed to determine the molecular mechanisms of IL-32 in osteosarcoma cells.

\section{Materials and methods}

Reagents and cell culture. Recombinant IL-32 was purchased from R\&D Systems (Minneapolis, MN, USA). AKT selective inhibitor LY294002 was purchased from Calbiochem (San Diego, CA, USA). Antibody of IL-32 was obtained from Abcam (Cambridge, UK). Antibodies of AKT and phosphorylated AKT were obtained from Cell Signaling Technology, Inc. (Danvers, MA, USA). Antibody of $\beta$-actin was obtained from Sigma Aldrich (St. Louis, MO, USA). The MG-63 human osteosarcoma cell line was purchased from the American Type Culture Collection (ATCC, Manassas, VA, USA). Cells were incubated in Dulbecco's modified Eagle's medium (DMEM) supplemented with $10 \%$ fetal bovine serum (FBS) and maintained in $5 \% \mathrm{CO}_{2}$ at $37^{\circ} \mathrm{C}$ in a humidified incubator.

Invasion assay. Cell invasion ability was assessed using an invasion assay. Briefly, a 24-well Transwell plate was 
purchased from Costar (Corning, NY, USA) and the upper chambers were coated with Matrigel prior to use. The cells were adjusted to a concentration of $5 \times 10^{5} / \mathrm{ml}$ and then treated with different concentrations of IL-32 $(0,50,100$ and $200 \mathrm{ng} / \mathrm{ml}$ ). Subsequently, $200 \mu \mathrm{l}$ of cell suspension was added into the upper chambers, and $500 \mu 1$ DMEM supplemented with $20 \%$ FBS was added into the lower chambers. After $18 \mathrm{~h}$, the cells that invaded through the Matrigel-coated filters were fixed and stained with crystal violet. The invaded cells were counted under a microscope at a magnification of x200.

Wound-healing assay. Cell motility was assessed by a scratch wound-healing assay. The cells were seeded in a 6-well plate, cultured until confluent and then treated with or without IL-32 $(100 \mathrm{ng} / \mathrm{ml})$. The cell layer was wounded by a sterile tip and the spread of wound closure was observed after $18 \mathrm{~h}$ under a microscope at a magnification of $\mathrm{x} 100$.

RNA interference (RNAi) assay. Small-interfering RNA (siRNA) was designed and obtained from Shanghai GeneChem (Shanghai, China). Using Lipofectamine 2000 reagent (Invitrogen, Carlsbad, CA, USA), MG-63 cells were transfected with an IL-32 siRNA (5'-GCUCACUCCUCUACUU GAA-3') or a scramble control siRNA (5'-UGGUUUACAUGUUUUC UGA-3'). The cells were then incubated for $48 \mathrm{~h}$ and the knockdown efficiency was assessed by western blot analysis.

Western blot analysis. Cell lysates were extracted by RIPA lysis buffer supplemented with protease and phosphatase inhibitors (Applygen Technologies, Inc., Beijing, China), and then the BCA method was used to measure the concentration of total protein. An equal amount of protein was separated by SDS-PAGE gels and then transferred onto a PVDF membrane. The membrane was then blocked for $1 \mathrm{~h}$ in TBST containing $5 \%$ BSA, and subsequently immunoblotted with primary antibody overnight at $4^{\circ} \mathrm{C}$. After washing with TBST, the membrane was incubated for $1 \mathrm{~h}$ with secondary antibody. Finally, the bands were visualized via chemiluminescence using an ECL Detection kit (Applygen Technologies).

$R T-P C R$. Total RNA was extracted using TRIzol reagent (Invitrogen), as per the manufacturer's instructions. Reverse transcription was performed to obtain cDNA using the RevertAid First Strand cDNA synthesis kit (Fermentas, Burlington, Ontario, Canada). Subsequently, $2 \mu \mathrm{g}$ of cDNA was amplified with the primers of matrix metalloproteinase (MMP)-13 (F, 5'-ACTGAGAGGCTCCGAGAAATG-3' and R, 5'-GAACC CCGCATCTTGGCTT-3'); and $\beta$-actin (F, 5'-ATAGCACA GCCTGGATAGCAACGTAC-3' and R, 5'-CACCTTC TACAATGAGCTGCGTGTG-3') using a SYBR-Green PCR kit (Applied Biosystems, Carlsbad, CA, USA). RT-PCR analysis was performed using the following cycle parameters: $10 \mathrm{~min}$ at $95^{\circ} \mathrm{C}$, and then 40 cycles of $15 \mathrm{sec}$ at $95^{\circ} \mathrm{C}$ and $1 \mathrm{~min}$ at $60^{\circ} \mathrm{C} . \beta$-actin was used as internal control and the relative expression of MMP-13 was determined by the $2^{-\Delta \Delta \mathrm{Ct}}$ method.

ELISA. The cells were incubated with or without IL-32 (100 ng/ $\mathrm{ml}$ ) for $18 \mathrm{~h}$. The cell supernatant was collected and stored at $-80^{\circ} \mathrm{C}$ until the ELISA was performed. The MMP-13 protein level in the cell supernatant was assessed by the MMP-13
ELISA kit (Millipore, Billerica, MA, USA), according to the manufacturer's instructions.

Statistical analysis. The experiments were performed at least three times. Data were presented as mean \pm standard error of the mean. The data were analyzed using SPSS software (version 18.0). Comparisons between any two groups were assessed by the Student's t-test and comparisons among multiple groups were assessed by one-way analysis of variance (ANOVA). $\mathrm{P}<0.05$ was considered to indicate a statistically significant result.

\section{Results}

IL-32 promotes the invasion and motility of osteosarcoma cells. In order to investigate the role of IL-32 in the invasion of osteosarcoma cells, MG-63 cells were stimulated with different concentrations of IL-32 $(0,50,100$ and $200 \mathrm{ng} / \mathrm{ml})$ and then an invasion assay was performed. The results showed that IL-32 stimulation promoted the invasion of MG-63 cells in a dose-dependent manner (Fig. 1A). Furthermore, the effect of IL-32 on cell motility was determined by the wound-healing assay. Notaby, the results showed that IL-32 stimulation led to a significant increase in MG-63 cell motility (Fig. 1B). These results indicated that IL-32 stimulation enhances the invasion and motility of osteosarcoma cells.

Knockdown of IL-32 suppressed the invasion and motility of osteosarcoma cells. To examine whether endogenous IL-32 can affect the invasion and motility of osteosarcoma cells, we silenced the expression of IL-32 in MG-63 cells by siRNA. Western blot analysis revealed that the endogenous expression of IL-32 was efficiently repressed by siRNA IL-32 (Fig. 2A). Resutls of the invasion and wound-healing assays showed that knockdown of IL-32 markedly inhibited the invasion and motility abilities of MG-63 cells, supporting the hypothesis that IL-32 is important in osteosarcoma cell invasion and motility (Fig. 2B and C).

IL-32 stimulation induces the activation of AKT. Multiple signaling pathways have been observed to be activated by IL-32 (13). In the present study, we studied whether IL-32 stimulation affected the activation of AKT in osteosarcoma cells. The results showed that IL-32 $(100 \mathrm{ng} / \mathrm{ml})$ induced the activation of AKT in a time-dependent manner, with peak activation occurring at $30 \mathrm{~min}$ (Fig. 3), indicating that IL-32 induces the activation of AKT in osteosarcoma cells.

$I L-32$ increases the expression and secretion of MMP-13. Since the MMPs are essential for the invasion and metastasis of tumor, we assessed whether IL-32 affected MMPs expression in osteosarcoma cells. MG-63 cells were stimulated with or without IL-32 $(100 \mathrm{ng} / \mathrm{ml})$ for 12 or $18 \mathrm{~h}$, and the mRNA levels of MMP-2, MMP-9 and MMP-13 were detected by RT-PCR. The results showed that the mRNA expression of MMP-13 in MG-63 cells was markedly increased after IL-32 stimulation (Fig. 4A). Thus, we further examined the effect of IL-32 on MMP-13 secretion in MG-63 cells. ELISA showed that IL-32 stimulation resulted in increased protein secretion of MMP-13 in MG-63 cells (Fig. 4B). These results suggested 

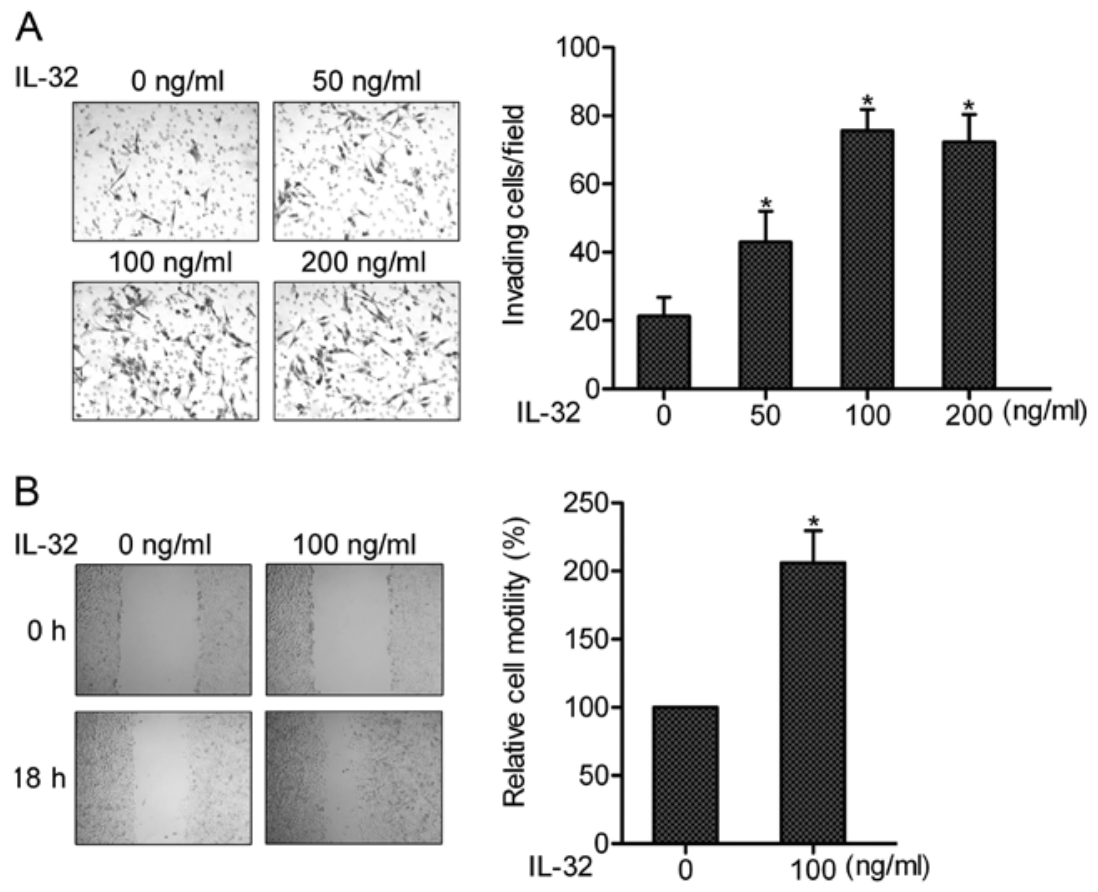

Figure 1. IL-32 stimulation resulted in an increase in osteosarcoma cell invasion and motility. (A) Effect of IL-32 stimulation $(0,50,100 \mathrm{and} 200 \mathrm{ng} / \mathrm{ml})$ on cell invasion was detected by an invasion assay. (B) Effect of IL-32 stimulation $(100 \mathrm{ng} / \mathrm{ml})$ on cell motility was detected by a wound-healing assay. "P<0.05.

A
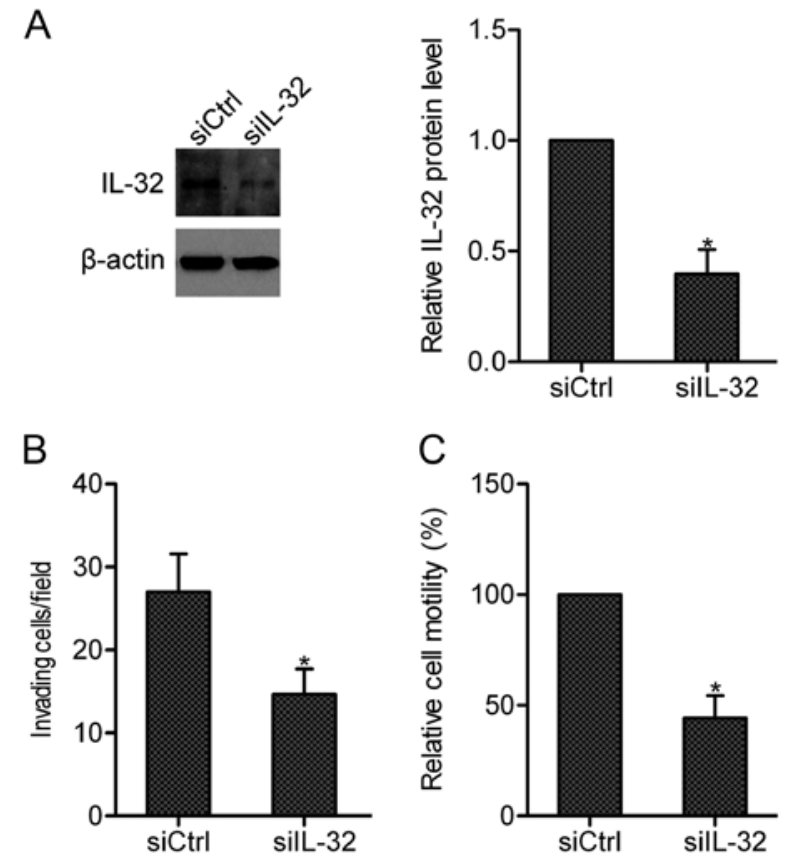

Figure 2. Knockdown of IL-32 inhibited osteosarcoma cell invasion and motility. (A) Western blot analysis showed that IL-32 expression in MG-63 cells was efficiently silenced by IL-32 siRNA. (B) Knockdown of IL-32 suppressed the invasion of MG-63 cells. (C) Knockdown of IL-32 suppressed the motility of MG-63 cells. ${ }^{*} \mathrm{P}<0.05$.

that IL-32 stimulates the expression and secretion of MMP-13 in osteosarcoma cells.

AKT pathway is involved in IL-32-enhanced cell invasion and motility. To detect the role of AKT pathway in IL-32-mediated invasion and motility, LY294002, a selective AKT inhibitor,
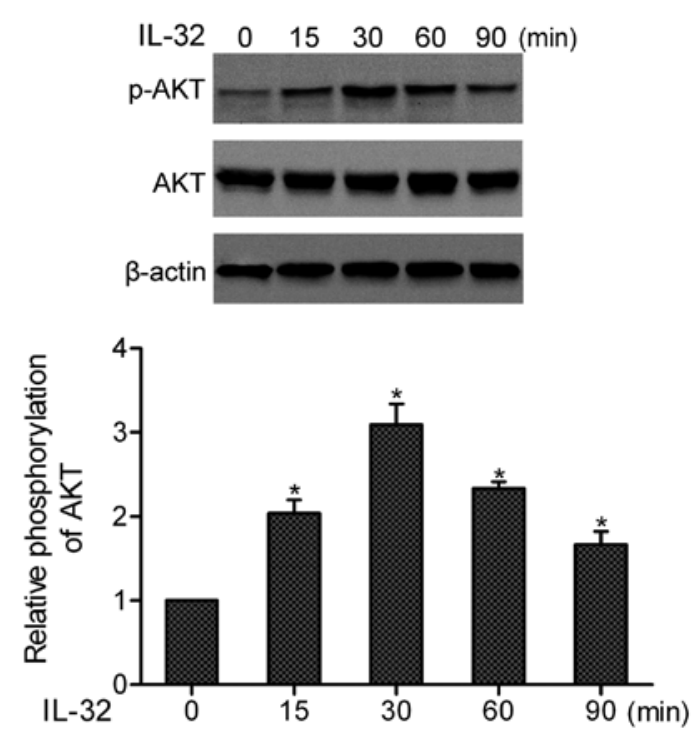

Figure 3. IL-32 stimulation time-dependently induced the activation of AKT. MG-63 cells which were stimulated with IL-32 (100 ng/ml). The phosphorylation of AKT at 0, 15, 30, 60 and 90 min was detected by western blot analysis. ${ }^{*} \mathrm{P}<0.05$.

was added to MG-63 cells prior to IL-32 stimulation. The results showed that IL-32 stimulated the invasion and motility in the DMSO-treated group. However, after inhibition of AKT by LY294002, the invasion and motility abilities of MG-63 cells were markedly suppressed, suggesting the involvement of AKT pathway in IL-32-enhanced invasion and motility in osteosarcoma cells (Fig. 5).

IL-32 regulates MMP-13 expression and secretion via the AKT pathway. We verified the effect of AKT activation on 

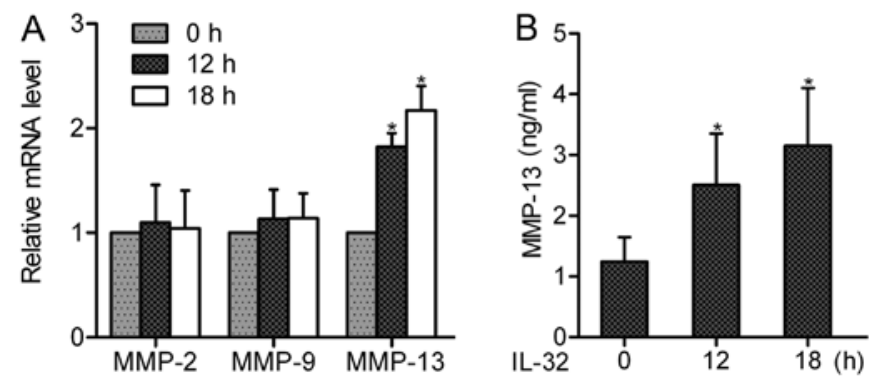

Figure 4. IL-32 upregulated the expression and secretion of MMP-13. (A) The mRNA levels of MMP-2, MMP-9 and MMP-13 were detected by RT-PCR in MG-63 cells stimulated with IL-32 (100 ng/ml). (B) MG-63 cells were treated with IL-32 $(100 \mathrm{ng} / \mathrm{ml})$ for 12 or $18 \mathrm{~h}$, and then the protein levels of MMP-13 in the cell supernatant was determined by ELISA assay. ${ }^{*} \mathrm{P}<0.05$.
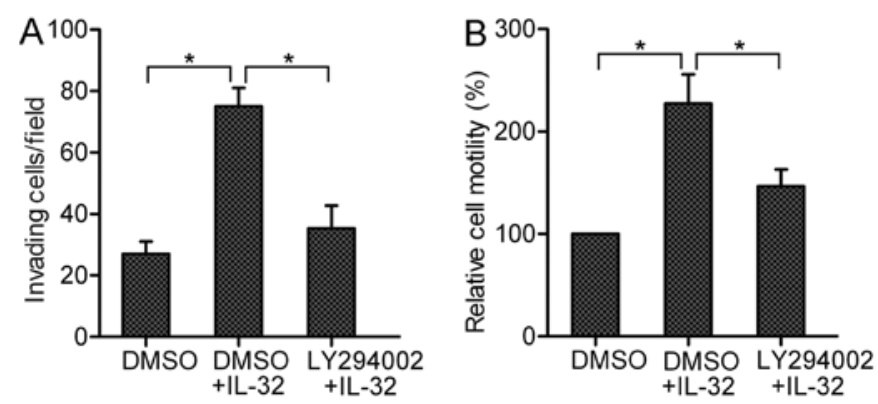

Figure 5. IL-32 promoted osteosarcoma cell invasion and motility via activation of the AKT pathway. MG-63 cells were treated with LY294002 (AKT inhibitor, $10 \mu \mathrm{M}$ ) for $30 \mathrm{~min}$ prior to IL-32 $(100 \mathrm{ng} / \mathrm{ml})$ stimulation. (A) Invasion and (B) wound healing assays were performed to determine the role of AKT pathway in IL-32-mediated cell invasion and motility. ${ }^{*} \mathrm{P}<0.05$.

the IL-32-regulated MMP-13 production. RT-PCR and the ELISA showed that when AKT activation was blocked by LY294002 prior to IL-32 stimulation, the mRNA expression and protein secretion of MMP-13 induced by IL-32 stimulation were significantly inhibited (Fig. 6), suggesting that IL-32 upregulates MMP-13 expression and secretion dependent on AKT activation.

\section{Discussion}

As a member of the inflammatory cytokines, IL-32 has been found to be invovled in the progression of cancer. Previous findings have shown that IL-32 exerts antitumor activity by inhibiting cell growth and inducing cell apoptosis in various types of cancer, such as colon cancer and hepatocellular carcinoma $(14,15)$. However, IL-32 is able to promote the tumorigenesis of colon cancer cells (16), and stimulate the angiogenesis of endothelial cells (17). IL-32 has been shown to be associated with the invasion and metastasis of gastric and lung cancer $(18,19)$. Moreover, experimental data have demonstrated that IL-32 stimulates the migration of breast cancer cells (20), and increases the invasion and metastasis of gastric and lung cancer cells $(21,22)$, indicating that IL-32 is a crucial mediator for tumor invasion and metastasis. IL-32 acts as a potent modulator of osteoclastogenesis (23); however, little is known concerning the effect of IL-32 on osteosarcoma. In the present study, we found that IL-32 stimulation
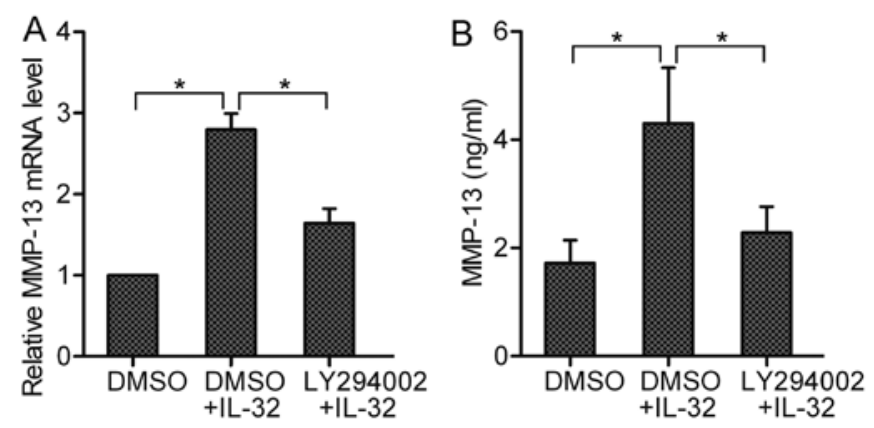

Figure 6. IL-32 upregulated MMP-13 expression and secretion through AKT activation. MG-63 cells were treated with LY294002 (AKT inhibitor, $10 \mu \mathrm{M}$ ) for $30 \mathrm{~min}$ prior to IL-32 (100 ng/ml) stimulation. After $18 \mathrm{~h}$, (A) RT-PCR and (B) ELISA assay were performed to detect the effect of AKT blockade on the IL-32-mediated MMP-13 expression and secretion in osteosarcoma cells. ${ }^{*} \mathrm{P}<0.05$.

dose-dependently increased the invasion and motility of osteosarcoma cells, and knockdown of endogenous IL-32 by siRNA significantly inhibited osteosarcoma cell invasion and motility. These results strongly support the hypothesis that IL-32 contributes to the invasion and motility of osteosarcoma cells.

Although the receptor for IL-32 is not well established, studies have proven that IL-32 stimulation leads to the activation of multiple signaling pathways, including ERK1/2, p38 and nuclear factor (NF)- $\kappa \mathrm{B}$ pathways $(24,25)$. It is reported that IL-32 treatment induces a massive activation of AKT in osteoclast (23). Previous findings have shown that IL-32 stimulates the activation of AKT in gastric cancer cells (21). Similarly, we found that IL-32 stimulation time-dependently induced the activation of AKT. The AKT pathway is known to be essential for tumor invasion and metastasis (26). In the present study, inhibition of the AKT pathway markedly attenuated IL-32-enhanced osteosarcoma cell invasion and motility, indicating that IL-32 may promote the invasion and motility of osteosarcoma cells by activating the AKT pathway.

MMP-13 is an important member of the MMP family, and plays a pivotal role in tumor cell invasion and metastasis processes via the degradation of the extracellular matrix (ECM) (27). In the present study, we showed that IL-32 upregulated the expression and secretion of MMP-13 in osteosarcoma cells. In addition, we found that the AKT pathway was required for IL-32-mediated MMP-13 upregulation. Previous studies have reported the involvement of MMP-13 in the regulation of osteosarcoma progression (28-30). Therefore, it is possible that AKT pathway-mediated MMP-13 upregulation participates in IL-32-promoted osteosarcoma cell invasion and motility.

In summary, the present study has demonstrated that IL-32 is capable of promoting the invasion and motility in osteosarcoma cells. The activation of AKT and subsequent upregulation of MMP-13 production contributes to the biological functions of IL-32. Thus, IL-32 acts as a potential therapeutic target for osteosarcoma.

\section{Acknowledgements}

The present study was supported by grants from the National Natural Science Foundation of China (no. 81260274). 


\section{References}

1. Heare T, Hensley MA and Dell'Orfano S: Bone tumors: osteosarcoma and Ewing's sarcoma. Curr Opin Pediatr 21: 365-372, 2009.

2. Broadhead ML, Clark JC, Myers DE, Dass CR and Choong PF: The molecular pathogenesis of osteosarcoma: a review. Sarcoma 2011: 959248, 2011

3. Kakhki VR, Anvari K, Sadeghi R, Mahmoudian AS and Torabian-Kakhki M: Pattern and distribution of bone metastases in common malignant tumors. Nucl Med Rev Cent East Eur 16: 66-69, 2013.

4. Wu PK, Chen WM, Chen CF, Lee OK, Haung CK and Chen TH: Primary osteogenic sarcoma with pulmonary metastasis: clinica results and prognostic factors in 91 patients. Jpn J Clin Oncol 39: 514-522, 2009.

5. Sheu BC, Chang WC, Cheng CY, Lin HH, Chang DY and Huang SC: Cytokine regulation networks in the cancer microenvironment. Front Biosci 13: 6255-6268, 2008.

6. Wilson J and Balkwill F: The role of cytokines in the epithelial cancer microenvironment. Semin Cancer Biol 12: 113-120, 2002.

7. Kim SH, Han SY, Azam T, Yoon DY and Dinarello CA: Interleukin-32: a cytokine and inducer of TNFalpha. Immunity 22: 131-142, 2005.

8. Netea MG, Azam T, Ferwerda G, et al: IL-32 synergizes with nucleotide oligomerization domain (NOD) 1 and NOD2 ligands for IL-1beta and IL-6 production through a caspase 1-dependent mechanism. Proc Natl Acad Sci USA 102: 16309-16314, 2005.

9. Choi JD, Bae SY, Hong JW, et al: Identification of the most active interleukin-32 isoform. Immunology 126: 535-542, 2009.

10. Yagi Y, Andoh A, Imaeda H, et al: Interleukin-32 $\alpha$ expression in human colonic subepithelial myofibroblasts. Int J Mol Med 27: 263-268, 2011.

11. Yousif NG, Al-Amran FG, Hadi N, Lee J and Adrienne J: Expression of IL-32 modulates NF-kappaB and p38 MAP kinase pathways in human esophageal cancer. Cytokine 61: 223-227, 2013.

12. Lee HJ, Liang ZL, Huang SM, et al: Overexpression of IL-32 is a novel prognostic factor in patients with localized clear cell renal cell carcinoma. Oncol Lett 3: 490-496, 2012.

13. Joosten LA, Heinhuis B, Netea MG and Dinarello CA: Novel insights into the biology of interleukin-32. Cell Mol Life Sci 70 3883-3892, 2013.

14. Kang YH, Park MY, Yoon DY, et al: Dysregulation of overexpressed IL-32alpha in hepatocellular carcinoma suppresses cell growth and induces apoptosis through inactivation of NF-kappaB and Bcl-2. Cancer Lett 318: 226-233, 2012.

15. Oh JH, Cho MC, Kim JH, et al: IL-32gamma inhibits cancer cell growth through inactivation of NF-kappaB and STAT3 signals. Oncogene 30: 3345-3359, 2011.
16. Chang CJ, Chien Y, Lu KH, et al: Oct4-related cytokine effects regulate tumorigenic properties of colorectal cancer cells. Biochem Biophys Res Commun 415: 245-251, 2011.

17. Nold-Petry CA, Rudloff I, Baumer Y, et al: IL-32 promotes angiogenesis. J Immunol 192: 589-602, 2014.

18. Ishigami S, Arigami T, Uchikado Y, et al: IL-32 expression is an independent prognostic marker for gastric cancer. Med Oncol 30: 472, 2013

19. Sorrentino C and Di Carlo E: Expression of IL-32 in human lung cancer is related to the histotype and metastatic phenotype. Am J Respir Crit Care Med 180: 769-779, 2009.

20. Park JS, Choi SY, Lee JH, et al: Interleukin-32beta stimulates migration of MDA-MB-231 and MCF-7 cells via the VEGFSTAT3 signaling pathway. Cell Oncol (Dordr) 36: 493-503, 2013.

21. Tsai CY, Wang CS, Tsai MM, et al: Interleukin-32 increases human gastric cancer cell invasion associated with tumor progression and metastasis. Clin Cancer Res 20: 2276-2288, 2014.

22. Zeng Q, Li S, Zhou Y, et al: Interleukin-32 contributes to invasion and metastasis of primary lung adenocarcinoma via NF-kappaB induced matrix metalloproteinases 2 and 9 expression. Cytokine 65: 24-32, 2014.

23. Mabilleau G and Sabokbar A: Interleukin-32 promotes osteoclast differentiation but not osteoclast activation. PLoS One 4: e4173, 2009.

24. Cho KS, Park SH, Joo SH, Kim SH and Shin CY: The effects of IL-32 on the inflammatory activation of cultured rat primary astrocytes. Biochem Biophys Res Commun 402: 48-53, 2010.

25. Felaco P, Castellani ML, De Lutiis MA, et al: IL-32: a newlydiscovered proinflammatory cytokine. J Biol Regul Homeost Agents 23: 141-147, 2009.

26. Brader S and Eccles SA: Phosphoinositide 3-kinase signalling pathways in tumor progression, invasion and angiogenesis. Tumori 90: 2-8, 2004

27. Balbin M, Pendas AM, Uria JA, Jimenez MG, Freije JP and Lopez-Otin C: Expression and regulation of collagenase-3 (MMP-13) in human malignant tumors. APMIS 107: 45-53, 1999.

28. Ye Z, Jingzhong L, Yangbo L, Lei C and Jiandong Y: Propofol inhibits proliferation and invasion of osteosarcoma cells by regulation of microRNA-143 expression. Oncol Res 21: 201-207, 2014.

29. Osaki M, Takeshita F, Sugimoto Y, et al: MicroRNA-143 regulates human osteosarcoma metastasis by regulating matrix metalloprotease-13 expression. Mol Ther 19: 1123-1130, 2011.

30. Ma O, Cai WW, Zender L, et al: MMP13, Birc2 (cIAP1), and Birc3 (cIAP2), amplified on chromosome 9, collaborate with p53 deficiency in mouse osteosarcoma progression. Cancer Res 69: 2559-2567, 2009. 